\title{
JUVENILE FAMILIAL MOSAIC DEGENERATION OF THE CORNEA ASSOCIATED WITH MEGALOCORNEA*
}

\author{
BY
}

\section{B. BOLES CARENINI}

From the Ophthalmological Department of the University of Genoa (Director: Prof. A. Grignolo)

THE classification of the heredo-familial degenerations of the cornea proposed by Franceschetti and Forni (1950) and Franceschetti (1954), includes among the degenerations of the anterior limiting membrane (Bowman's) a rather rare manifestation called "mosaic degeneration". Because of its rarity, and because of certain unusual features, we have considered it worth while to report three cases recently observed.

The patients were three out of five brothers (Fig. 1), the oldest and the youngest of whom showed no ocular abnormalities. The father and mother had both been dead for some time but, according to their sons, they had enjoyed good eyesight until late in life. As far as could be ascertained there was no consanguinity.

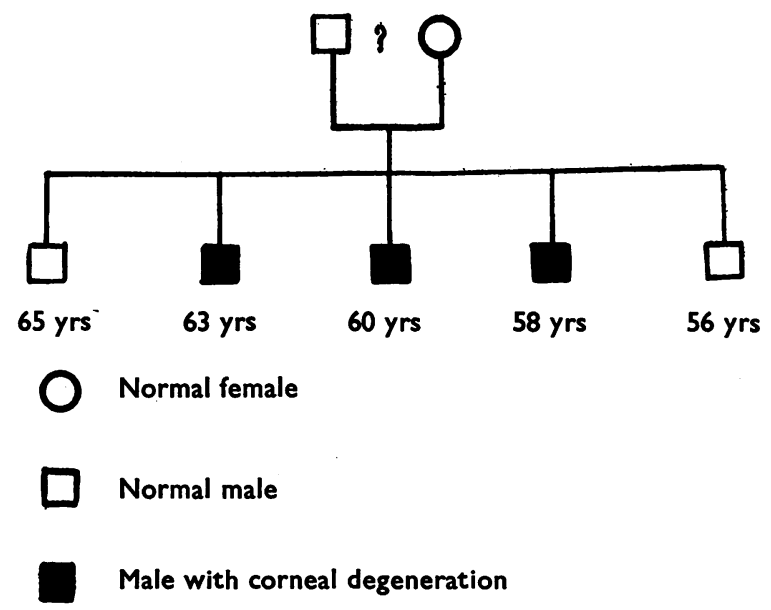

FIG. 1.-Family tree, showing three out of five brothers affected.

* Received for publication January 1, 1960. 


\section{Case Reports}

Case 1, a married agricultural worker aged 63, from Luna Matrona (Sardinia), had developed normally after a normal birth. He had attended a primary school, and done his compulsory military service, and had had no significant illnesses.

His eyesight had been good until he was about 40 years old, when a progressive visual deficiency developed in the right eye. When he was 47 years old, a cataract extraction had been performed on this eye; 2 or 3 years later the sight in the left eye had decreased until it was limited to seeing hand movements at $50 \mathrm{~cm}$., and he was admitted to our clinic with a diagnosis of senile cataract.

Examination-Right Eye.-The ocular adnexa were normal; the cornea (Fig. 2) showed an increased diameter of 14 to $15 \mathrm{~mm}$. (megalocornea), and was slightly thinner in the middle where sensitivity appeared to be less than at the periphery. A greyish opacity, occupying almost the whole of the cornea with the exception of a peripheral zone of some $3 \mathrm{~mm}$., was visible in diffuse light. This opacity appeared to consist of numerous small round or polygonal greyish spots (about $0.2 \mathrm{~mm}$.), arranged in a mosaic pattern and separated from each other by darker lines of almost transparent tissue. The alterations were localized in the layer of Bowman's membrane and the other corneal layers were of normal appearance. The anterior chamber was deeper than normal, with iridodonesis, and surgical aphakia. There was a basal surgical iris coloboma at 12 o'clock. The fundus appeared normal. The intra-ocular pressure was $15 \mathrm{~mm}$. $\mathbf{H g}$ (Schiötz). The visual acuity (with correction $+9 \mathrm{D}$ sph., $+1 \mathrm{D}$ cyl., axis $180^{\circ}$ ) was $10 / 10$. The visual field was normal.

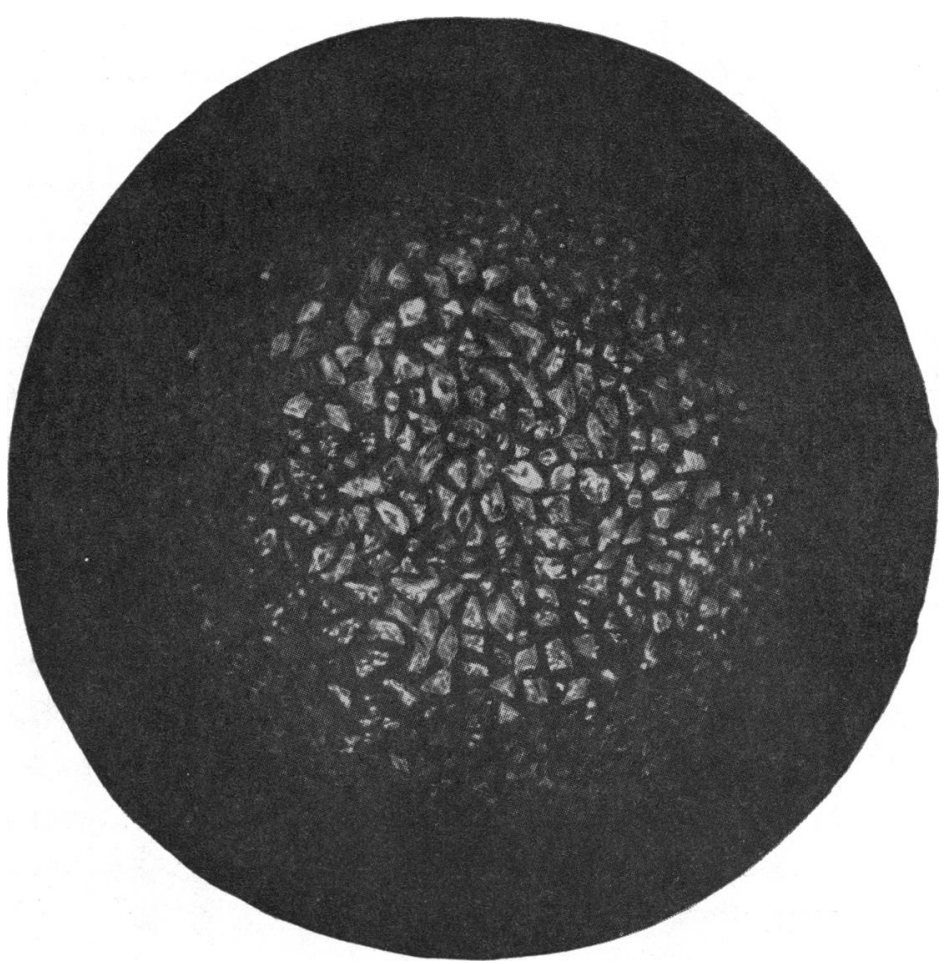

FIG. 2.-Corneal appearance in Case 1. 
Left Eye.-The appearance was identical with that in the right eye as regards the appearance of the cornea; and there was a complete cataract with no unusual characteristics. The intra-ocular pressure was $15 \mathrm{~mm}$. $\mathrm{Hg}$ (Schiötz). The visual acuity was hand movements at $50 \mathrm{~cm}$., and light projection and colour perception were good.

Additional investigations carried out in hospital revealed the following:

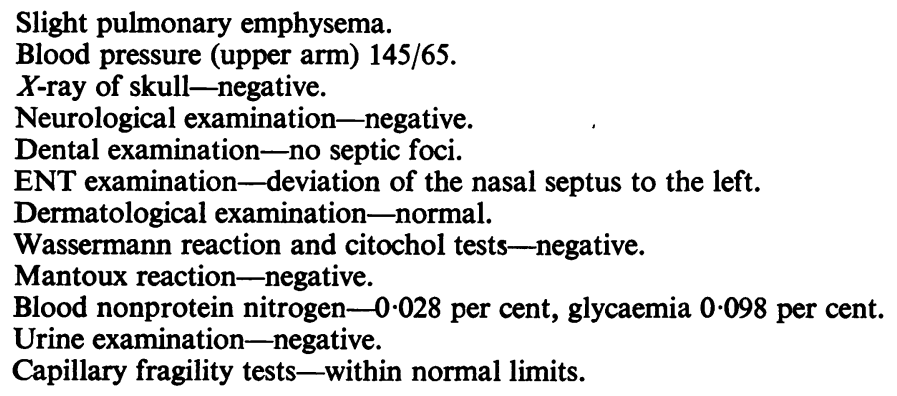

An intracapsular cataract extraction in the left eye was carried out in August, 1958. The post-operative course was normal and after 45 days the visual acuity was 10/10 with +11 D sph., + 1 D cyl., axis $180^{\circ}$.

Case 2, an unmarried agricultural worker aged 60, from Aleo (Sardinia), younger brother of Case 1, had developed normally after a normal birth, and had attended a primary school, but had been rejected for military service on account of poor visual acuity; he had had no significant illnesses.

The visual acuity had always been less than normal, and about the age of 30 a further deterioration had occurred, affecting both eyes. At age 33 he had undergone a bilateral cataract extraction, and bilateral corneal opacities were noted.

Examination-Right Eye.-The ocular adnexa were normal. The corneal diameter was enlarged to $15-16 \mathrm{~mm}$. (megalocornea) with a slight central thinning and diminished sensitivity. At the centre there was a round opacity some $8 \mathrm{~mm}$. in diameter, consisting of small separate spots, some more or less polygonal, others round and separated from each other by lines of normal tissue; this mosaic pattern was more evident at the centre, and towards the periphery the opacity showed a progressive diffusion in the normal corneal tissue. The opacities were localized in Bowman's membrane, the epithelium and other corneal layers appearing intact. The anterior chamber was deeper than normal, with iridodonesis, and surgical aphakia. A large basal surgical coloboma was visible at 12 o'clock. The fundus was normal. The intra-ocular pressure was $18 \mathrm{~mm}$. $\mathrm{Hg}$ (Schiötz). The visual acuity (with correction $+11 \mathrm{D}$ sph.) was 10/10. The visual field was normal.

Left Eye.-The appearance of the cornea was similar to that in the right eye. There was a large total iris coloboma at 12 o'clock, with lenticular sequelae in the pupillary field. The fundus showed large spots of diffuse pigmented atrophy along the inferior temporal vessels. The intra-ocular pressure was $16 \mathrm{~mm}$. $\mathrm{Hg}$ (Schiötz). The visual acuity (with correction $+11 \mathrm{D}$ sph.) was $9 / 10$.

General examination in the out-patients' department gave negative results in every respect.

Case 3, an unmarried agricultural worker aged 58, younger brother of Cases 1 and 2, from Luna Matrona (Sardinia), had developed normally after a normal birth, and had attended a primary school and done his military service. He had had no significant illnesses, with 
the exception of malaria at age 15. He had always had good eyesight and still could see well.

Examination-Both Eyes.-The ocular adnexa were normal. The cornea presented a diffuse central opacity, with maximal density in the central part blending into normal tissue towards the periphery. Slit-lamp examination revealed grey areas, rounded and polygonal, of various dimensions, separated by lines of more transparent tissue, more marked towards the centre. These opacities lay in Bowman's membrane, the epithelium and the deeper layers being intact. The anterior chamber, iris, lens, and fundus were normal. The intra-ocular pressure was $18 \mathrm{~mm}$. Hg (Schiötz). The visual acuity was $8 / 10$ without correction and could not be improved with lenses. The visual field was normal.

In this patient, also, all additional examinations gave negative results.

\section{Discussion}

These reports show that the three brothers all had megalocornea and corneal opacity; one of them also had a bilateral cataract, probably of congenital origin. The appearance and arrangement of the corneal opacities situated in Bowman's membrane are regarded as typical of mosaic degeneration of the cornea or, as Vogt (1930) called it, "Krokodil Chagrin der Membranae Bowmanii" (crocodile-skin Bowman's membrane). Vogt first observed and described this corneal alteration in an 80-year-old patient. He recorded its characteristic features as round or polygonal grey opacities, mostly situated predominantly in the centre and separated by darker linear spaces, situated in the anterior limiting membrane. Vogt regarded these lesions as senile in nature, but Valerio (1939) described a similar case in a man aged 25 years, in which the colour tended towards yellow. The opacities in Valerio's case had more sharply delimited margins and were densest near the centre of the cornea. The differences led Valerio to think that the two conditions were different stages in the same type of corneal degeneration. Later, however, after he had had the opportunity to observe this patient's father (who presented a bilateral degenerative lesion of the cornea similar to band-shaped opacity), Valerio (1942) was of the opinion that his case of mosaic degeneration, notwithstanding the similarity of the lesions, was not identical with that described by Vogt, but was rather as a lesion of a familial and dominant character; the difference in appearance between the lesions in the father and those in the son are presumably attributable to the different ages at onset.

If we disregard two cases described by Streiff (1948) in which the lesions, although morphologically the same, were situated in Descemet's membrane and therefore belonged to the posterior "Krokodil Chagrin der Membranae Descemeti" of Vogt, the third case of anterior mosaic degeneration is that reported by Müller (1949), who observed it in a patient who 5 years previously had had keratitis with hypopyon due to contusive trauma. The polygonal appearance of the lesions in Bowman's membrane was typical, but the opacities had more irregular dimensions than those in the cases of 
Vogt and of Valerio. Müller was able to make a histological examination of a corneal disc taken with lamellar transplantation. Under a markedly altered epithelium, he encountered large ruptures of Bowman's membrane. At the edges of these tears, the membrane curved backward almost at right angles; in some places it was normal in appearance and thickness, but elsewhere appeared thinned, granular, and ravelled. A layer of newly formed connective tissue was found between the Bowman capsule and the epithelium. The middle and deep layers of the corneal parenchyma appeared normal. Müller concluded that the greyish polygonal opacities corresponded to zones in which Bowman's membrane was present, morphologically altered, whereas the darker lines would be the evidence, demonstrable with the slit-lamp, of the ruptures of the membrane.

Moro and Amidei (1953) reported a case of bilateral mosaic degeneration in a patient aged 70 years. Histological examination revealed that, under a normal epithelium, Bowman's membrane showed no definite breaches but a very fine uniform stippling over almost the whole of the anterior part. The stippled zone did not pass beyond Bowman's membrane, and it was not of uniform depth. The separate stipples showed small variations in volume and could be clearly stained with both van Gieson and MayGrünwald-Giemsa stain. They did not dissolve in acid and were densest near the border with the basal layer of the epithelium. The parenchyma was normal. Moro and Amidei stated that in this case the biomicroscopic aspects of anterior mosaic degeneration were combined with the histological features of earlier senile band-shaped keratitis. Repeated examinations at regular intervals revealed that the initial mosaic pattern changed progressively until it became an opacity of uniform density in which the initial polygonal opacities could be recognized only with the greatest difficulty. They concluded that mosaic degeneration should not be regarded as a separate clinical entity but as a phase in a degenerative corneal process; the process may stop at this phase, but it may also develop further, leading to alterations not only of the Bowman's membrane but also of the epithelium and the superficial layers of the parenchyma, until the final stage of bandshaped keratitis is reached.

Kopša and Marušić (1958) reported five patients with mosaic degeneration aged between 18 and 52 years who were observed in two generations of the same family. The corneal alterations had first appeared in the second or third decade of life and although they had become aggravated, the pattern had always remained the same. These authors confirmed the dominant heredo-familial character of the degenerative form.

Among the most interesting aspects of the cases reported above is the number found in one family. With the exception of those reported by Kopša and Marušić, all the cases so far described have been isolated, and, if Müller's post-traumatic case is included, only nine examples have so far been published. 
The fact that the three patients were brothers confirms the heredo-familial character presumed by Valerio, and supported only by Kopša and Marušić. Since we were unable to study our patients' parents, we cannot confirm the dominant character of the heredity.

In all previously published cases the corneal changes caused loss of vision, but in our cases the visual acuity (after cataract operation and with suitable correction) was normal in Cases 1 and 2 and almost normal (9/10 binocular vision) in Case 3.

The association of mosaic degeneration of Bowman's membrane with megalocornea does not seem to have been observed before. Megalocornea has been observed with perilimbal semilunar shining opacities in Bowman's membrane (Berliner, 1949), but these in no way resembled the mosaic degeneration.

The age at onset could not be determined in our subjects, because Cases 1 and 3 had always enjoyed good eyesight and Case 2 had bilateral cataract. The association of a congenital defect such as megalocornea (plus, in one case at least, a congenital cataract) suggests that the corneal degeneration may have been present at birth or have developed soon after it. In one of our patients the corneal changes were first seen when he was 33 years old, so that it can definitely be considered juvenile. The identical appearance in all three patients suggests that the degeneration had manifested itself in the same period in each case, which would be in accordance with the observations of Kopša and Marušić. It therefore appears justifiable to distinguish (apart from the secondary post-traumatic form, Müller, 1949) a mosaic degeneration of senile type and an earlier, juvenile, and familial type (Table).

TABLE

VARIOUS FORMS OF MOSAIC DEGENERATION OF BOWMAN'S MEMBRANE

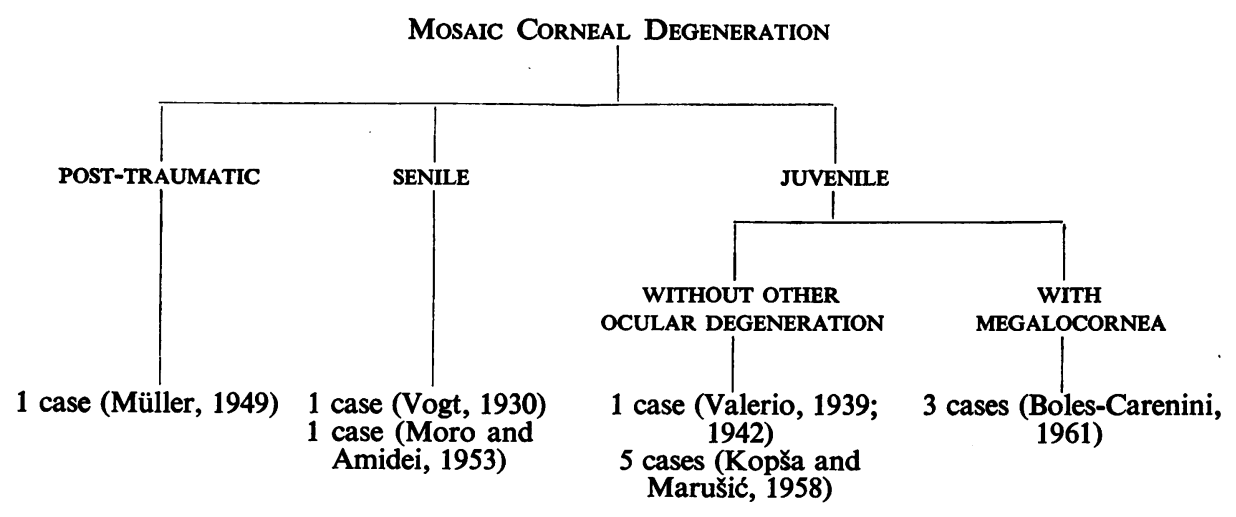

The senile form may vary in appearance, assuming the aspect of bandshaped keratitis, while the juvenile form begins before the 30th year and progresses to increasing density of the opacities without alteration in the 
objective findings. In the senile form, visual acuity is always greatly diminished, whereas in the juvenile form the degree of visual loss may vary from slight to severe. Also, the juvenile form may be associated with other congenital defects (megalocornea; cataract).

\section{Summary.}

The cases are reported of three brothers (out of a family of five) with bilateral mosaic degeneration of Bowman's membrane with megalocornea. One patient also had bilateral congenital cataract. The corneal degeneration became manifest in early middle age, and the visual acuity was not affected. Comparing his observations with nine other cases previously reported in the literature the author feels that this extremely rare type of corneal degeneration should be separated into two forms, senile and juvenile, differing in age at onset, the speed of progression, the degree of visual loss, and the heredo-familial character; the juvenile form may also be associated with other congenital ocular defects such as megalocornea and congenital cataract.

\section{REFERENCES}

Berliner, M. L. (1949). "Biomicroscopy of the Eye", vol. 1, p. 291. Hoeber, New York. FrANCESCHETTI, A. (1954). A.M.A. Arch. Ophthal., 52, 1. and ForNI, S. (1950). "XVI Conc. Ophthal. 1950 Britannia Acta", p. 193. B.M.A., London.

KoPŠA, M., and MARUšrć, K. (1958). Ophthalmologica (Basel), 136, 83.

MORO, F., and AMIDEI, V. (1953). G. ital. Oftal., 6, 444.

MÜLleR, P. (1949). Ann. Oculist. (Paris), 182, 122.

STREIFF, E. B. (1948). Ophthalmologica (Basel), 116, 125.

VALERIO, M. (1939). Boll. Oculist., 18, 659.

- (1942). Arch. Ottal., 49, 76.

VoGT, A. (1930). "Lehrbuch und Atlas der Spaltlampenmikroskopie des lebenden Auges", vol. 1, p. 120. Springer, Berlin. 